Draft version - Final version published as Lagendijk, A. en Cornford, J.R. (2000):

Regional institutions and knowledge - tracking new forms of regional development policy, Geoforum, 31, 209-218

\title{
Regional institutions and knowledge - tracking new forms of regional development policy
}

Arnoud Lagendijk ${ }^{*}$ and James Cornford ${ }^{* *}$

*University of Nijmegen

Faculty of Policy Sciences

PO Box 9108

Nijmegen

6500 HK, The Netherlands

${ }^{* *}$ Centre for Urban and Regional Development Studies (CURDS)

University of Newcastle upon Tyne

NE1 7RU,

UK

Email: a.lagendijk@bw.kun.nl or james.cornford@ncl.ac.uk

\section{Abstract}

This paper is concerned to explore the role of concepts in regional development. It attempts to apply some of the lessons of recent work in organisational theory and science and technology studies to the field of regional development studies. Specifically, we seek to outline a social constructivist perspective on knowledge in 
regional development studies. One issue which this perspective raises is how convergence of organisational forms and procedures in the area of regional development has been coupled with an increasing focus on regional uniqueness. 
Introduction: knowledge and the development industry

The last twenty years have seen the emergence of a veritable regional development industry in Europe focused around the task of improving the competitive position of regions. The map of European regions is scattered with thick undergrowth of development agencies, technology transfer centres, training organisations and consultancy companies, encouraged and supported by the establishment and growth of the European Commission's Structural Funds and funding from national governments. This ensemble of agencies constitutes a significant industry in its own right.

As with other industries, the regional development industry has a seemingly inexhaustible thirst for concepts, notions, theories and models which can help organisations to undertake the task of developing regional economies. A frantic round of conferences, seminars, symposia and workshops have been established to aid the circulation of ideas around the development industry. A plethora of reports and consultancy studies, many funded by the European Commission, similarly help to spread not only facts about regional development, but also interpretations of those facts. In short, the regional development industry resembles the description of Mode II knowledge given by Gibbons et al (1994). While Mode I knowledge is disciplinarybased, hierarchical, science-oriented, and based on the linear model of knowledge flows, Mode II knowledge is, in contrast, trans-disciplinary, heterogeneous, organisationally heterarchical and transient, more 'socially accountable and reflexive'; it is also based on more diverse factors of supply and faces more differentiated forms of demand. 
Within the Regional Development industry, knowledge, its production (innovation), acquisition (learning), accumulation, storage and management has become an increasingly central issue, as in other industries. Most regional development studies literature has focused on the way in which firms and the business support infrastructure (technology transfer centres, regional development agencies, universities, etc.) innovate, learn, and manage and transfer knowledge. However, regional development studies is, of course, itself engaged in all of these tasks. Thus for us to study knowledge in regional development is, in an important respect, different from studying other aspects of regional development for the simple reason that academic researchers are themselves one significant source, store and dissemination route for knowledge. Exploring knowledge in regional development studies therefore requires us to reflect on our own practices, to place our own practices within the field of study.

This paper arises from that recognition. It was prompted by reflecting on our experiences working as regional development "consultants" which have brought us into contact with regional development agencies, consultants and other agencies, such the European Commission, as well as academic researchers. What we have noted, as we have gone from office to office to seminar room to conference to workshop, and as we have read books, reports, web pages and strategy documents, is that certain concepts, concepts which give a central role to knowledge and learning, crop up again and again. (Of course, it is sometimes we who introduce these concepts, but more often, they are already present.) The significance of knowledge and learning is, of course, one of the truisms of contemporary economic discourse captured in such 
phases as 'the knowledge economy' (see e.g., OECD, 1996) and the 'learning economy' (Lundvall and Johnson, 1994), and the growth of fields such as 'knowledge management' (see e.g., Demarest, 1997). However, the concepts that we have noted in our everyday work are very specific in that they concentrate on knowledge with very specific properties, knowledge that is highly tacit, localised and untraded, embedded in localised networks of individuals and institutions, and which can thus form the basis for a region or locality's USP (unique selling proposition) or, more broadly, competitive advantage (Henry et al., 1996; Malmberg and Maskell, 1997).

What we want to propose in this paper is a theoretical basis for exploring the way in which these concepts have been carried around 'the development industry' and why it is this type of knowledge, and not other types, which have been given such attention. While we often feel the inclination to criticise concepts on the basis of their origin, verification or application, this is not the purpose of this essay. Our concern is not whether these concepts are "right", "correct" or "true", but rather how they have come to be understood and acted on as "right", "correct" or "true." Our focus is on how concepts are created and how they travel from one setting to another and how this journey changes both those concepts and those individuals and agencies working with them. In short, we are interested in how these concepts have become the common sense of the regional development industry. What we aim to do here is to use some of the analytical concepts that have emerged in the recent debates on knowledge to explore the way in which knowledge circulates around the regional development industry. 


\section{Organisational fields and actor-networks}

How might we approach the question of knowledge within the regional development industry? In a conventional view, the starting point for discussing concepts is to define them, and to give an account of how this definition has emerged and how it is applied in communication between agents. Concepts are thus primarily intermediaries which serve the articulation of ideas between agents. We want to propose an approach which attaches a stronger role to concepts, in which concepts themselves are endowed with the capacity to shape the behaviour of agents and shape the relationships between organisations. In such a view, the crucial point is what the concept represents in terms of its history, its place in a wider discourse and, crucially, the kinds of action it underpins. It is not so much the single definition that counts but the way a concept evolves, how it adopts different and diverging definitions and usages, how it is enrolled by particular actors and how it enrols particular tools or 'actants'. In this section, we want to introduce two bodies of work that are, we think, particularly relevant to this perspective - organisational fields and actor-networks - two bodies of work that have recently been usefully brought together by Stuart Clegg (1997).

\section{Organisational fields and circuits of power}

The first perspective that we find useful begins from the recognition of the general forces in the environment in which organisations operate and which have a strong impact on their organisational forms. This view has been articulated by authors who have elaborated on the concept of organisational fields, which can be defined as aggregations of organisations that are involved in similar activities. Using the concept of organisational fields, DiMaggio and Powell (1983) develop the idea of institutional 
isomorphism. They stress the fact that, despite the emphasis on variety and innovation at the level of individual actors and organisations, in reality many organisational fields show a strong tendency to increased homogeneity. They put forward three reasons for such homogeneity. First, organisations become increasingly similar where they compete for the same resources, and, for reasons of political and institutional legitimisation, need to adapt to the external environment. A second source of convergence lies in the norms and values emerging out of the professional spheres on which organisations draw, and a tendency to use similar sources for information on organisational change (notably consultants). Finally, inter-organisational interaction encourages imitation of organisational practices or even the copying of organisational structures. So, through either the 'market' in which organisation 'compete', the professional networks on which they draw, or the mimicking of peers, new models and ideas tend to diffuse rapidly through organisational fields and induce convergence.

Clegg has elaborated on the concept of organisational fields and its relational dimension, by further exploring the position of actors and organisations, and developing a new perspective on the role of power. In particular, Clegg follows the way power relations are articulated, ranging from actors with a high discretionary strategic power to fully dependent 'relay-agents', in what he calls circuits of power. Much attention is paid to the way that, through discourse and positioning strategies, dominant agents manipulate other actors: 
the articulation of interests by strategic agencies is (...) the medium and outcome of unique positioning over the discretion of others' positioning in the organisation field (Clegg, 1997, p.199).

Power is essentially seen as relational and situational. This relational concept of power, which follows the line established by Machiavelli and developed by Foucault, invokes a highly dynamic image of the development of organisational fields, driven by forces of both change and stabilisation. Importantly, power is not seen as a structural property of agents, although it can become dispositional through a process of stabilisation and reification. Thus, 'a theory of power must examine how the field of force in which power is arranged has been fixed, coupled and constituted in such a way that, intentionally or not, certain 'nodal points' of practice are privileged in this unstable and shifting terrain'(Clegg, 1997, p. 17). The nodal points, or 'obligatory passage points', are strong points of reference in organisational fields, and may consist of core institutions, core concepts, or core methods, against which the different interests of agents are defined.

The integrating framework in Clegg's work is the idea of circuits of power. One dimension of these circuits refers to the exertion of 'normal' power (i.e. 'power over') in a system where the positions of agents are stable and the 'nodal points' are fixed. A second dimension is that of disciplinary power - which corresponds to the forces of institutional isomorphism alluded to above, and can best be understood in terms of rules of practice. A third dimension refers to the deepest layer in the circuits, that of power which has the capacity to bring about fundamental shifts in the organisational field, modifying rules of practice, and the rules fixing meaning and membership. By 
distinguishing between these dimensions, Clegg is able to identify tendencies of convergence as well divergence, as well as including forces at the level of the organisational fields (such as institutional isomorphism) and the distinctive impact of agents and organisation in the field.

\section{The translation of interests through actor-networks}

The theories based on 'organisational fields' differ from the resource-based interpretations of organisations and networks in that they stress the relational aspects of organisational change and power. In Clegg's view, organisations are essentially loci of decision and action. Their power is defined by the way they are capable of mobilising or enrolling other actors and resources for their own interests. The key concepts in this mobilisation are the translation of interests. By translating interests efficiently and effectively, actors are able to appeal to other actors, to enrol them, to mobilise them, and to align and fix interest relationships in order to stabilise organisational configurations. Using the concepts of enrolment and translation, Clegg has managed to build a fruitful bridge between organisational theory and the theory of actor-networks (see e.g., Callon, 1991 and Latour 1997).

The concept of actor-network presents a provocative line of though which breaks with conventional thinking on agency, power and social relations. Callon and Latour start from a Machiavellian view of power, and develop a rich vocabulary around the central ideas of association, translation of interests, and the shaping of actor-networks. Rather than only focusing on associations of human agents, however, they include the role of non-human intermediaries such as technical artefacts, literary inscriptions and money. Actors can be defined as 'any entity able to associate texts, humans, non-humans and 
money.' (Callon, 1991, p.140). Through this association, an actor can be seen as both being a network, and as working through this network. In the words of Callon (1991, p.142): 'the network of intermediaries accepted by an actor after negotiation and transformation is in turn transformed by that actor - converted into a scenario, carrying the signature of its author, looking for actors ready to play its role. For this reason I speak of actor-networks.'

The emphasis on transformation and translation also reveals the emphasis on change and dynamism. Callon refers to 'punctualisation' as the process through which actornetworks become a single established point in a wider organisational field, corresponding to the 'obligatory passage points' mentioned above. Latour (1987) refers to these points as to black-boxes which, at least for a while, 'act as one'. Hence, an organisational field is characterised by the juxtaposition of various punctualised nodes, and different forms of co-ordination between actors established through a succession of translations. An important aspect of this dynamism is that it leaves nothing in the process of translation unchanged; it modifies the object, medium and subject of translation. It is a fundamental aspect of actor-network thinking that an actor, through his/her/its positioning and associational tactics, is also modified himself/herself/itself. (This opposes the notion in conventional social network theory in which an isolated actor, pursuing its presumed interests, engages in 'networking strategies').

What follows from this account is that the actor-network concept is particularly useful for tracking the unfolding of patterns of nodes and associations in organisational fields, and for analysing how this generates forms of emerging and 'established' 
wisdom and conventions for action. The crux of the actor-network perspective is not so much high theory but the presentation of a set of rules of method. The most essential of these rules defines the basic methodology of the approach: 'follow the actors'. An extensive example of how this methodology can be applied is illustrated by Latour's (1987) study of the development of scientific knowledge. Contradicting the conventional idea of scientific progress, he assesses the quality of knowledge statements not through their intrinsic properties, but through their subsequent translations and incorporations. Following the scientists, and tracking associations and translations he observes how 'artefacts' - essentially pieces of tacit knowledge - are translated into 'facts' and, for a certain time, into 'black boxes', before they are again dissolved and eroded. One paradoxical phenomenon Latour detects is that, in becoming 'black boxes', i.e. recognised points which 'act-as-one', actor-networks develop as highly complex webs of associations, involving ever more artefacts, humans, and, especially in the case of science, money. This view has important implications for a theory of knowledge creation and transfer. Rather than being literally 'codified', tacit knowledge is subsumed through the change in practices and texts, and carried further - in terms of both discourse and territory - through successive translations.

Pure actor-network thinking - which merely traces associations and translations faces a crucial problem when applied to practical research. There is little consideration of the larger context, background or frame within which the role of associations can be assessed. Without a method to differentiate between associations, and to interpret the absence of associations in certain situations, the approach is bound to suffer from 
what Law (1991 p.14) calls the 'despair of moral relativism'. Acknowledging this need for defining the actor-network in a wider perspective, and to offer some conceptualisation of agency, Callon (1997) introduces the idea of the framing of actors and their relations. The organisational field introduced earlier can be considered as the wider frame of reference in which actors operate.

We value Clegg's approach especially for the way he combines the method promoted by actor-network thinking with the structuring dimension of organisational fields. To understand the role of concepts, and the way they become 'nodal points', become black boxes, both dimensions are essential. On the one hand, the actor-network rules of method can shed light on how successive associations and translations contribute to the extension and power of concepts and their temporary domination as 'black boxes'. On the other hand, the organisational field offers both a context in the form of established rules of practice but which may also undergo fundamental shifts as a result of the emergence of new 'nodal points'. Finally, invoking organisational fields also allows us to explore the geographical dimension of processes of institutional change in a more structural (or generalisable) way.

\section{The knowledge agenda in the regional development industry}

How can these theories of organisational fields and actor-networks be applied to the power of particular concepts in the regional development industry? Our starting place for the discussion is to sketch out the regional development industry as an organisational field. The shaping of what has now become a burgeoning development industry can be related to a number of factors which are promoting a strong 
institutional isomorphism within the field. We would like to stress five factors in particular.

\section{The organisational field}

First, regional policy has moved from a top-down approach largely concerned with redistribution and physical investments to a more bottom-up approach focused on supply-side measures. ${ }^{1}$ Rather than concentrating on simply attracting jobs in the form of branch-plants, in the 1980s a new emphasis was placed on entrepreneurship and new firm formation together with the upgrading of the technological capacity of existing SMEs and improvements in the regional skills base. Achieving such goals implied the creation or expansion of a complex set of agencies and organisations that could intervene at the level of the (small- and medium-sized) firm, giving rise to in what may be loosely labelled "New Model" regional development agencies (Halkier and Damborg, 1997, Halkier and Danson, 1996). This approach suited a neo-liberal agenda which stresses innovation and the exploitation of 'indigenous capacity' as means to improve 'regional competitiveness'. The 'knowledge economy' appears prominently in the shaping of supply-side oriented regional development strategies. Many of the agencies involved are thus in the business of developing, absorbing and applying 'knowledge about knowledge', that is building their own intelligence base of how to improve the knowledge base of regional business.

Second, this shift towards a bottom-up, innovation oriented focus has been accompanied by a change in the funding of regional policy and business support. Increasingly, agencies rely on project funding, which is largely acquired in rounds of competitive bidding. Agencies have to learn to operate in a environment pervaded by a 
'challenge culture'; they also face a constant search by funding organisations for more effective, cheaper initiatives. This has raised the need for knowledge which allows agencies to budget and manage projects effectively and which also legitimates their actions and existence. One of the consequences of the emphasis on networking and the search for more cost-effective forms of business support has been that the role of government and support agencies is increasingly couched in terms of 'facilitators' and 'animateurs' (Cooke and Morgan, 1998).

Third, and closely linked to the first two points, the organisational environment in which agencies operate relies heavily on partnerships, both among development agencies, and between agencies and their customers. Partnerships have been sometimes imposed by funding conditions (for instance in the case of some Structural Funds programmes of the EU); often they have been triggered by the wish to strengthen the bidding power of participating organisations. The need for building partnerships has greatly increased the demand for knowledge, such as practical knowledge about partner search and network management, but also more fundamental concepts deployed in the forging and legitimisation of relationships and the drafting of joint projects.

Fourth, and responding to the increased demand for various types of knowledge, the organisational field has witnessed a growing significance of consultants and universities. Not only have these organisations benefited from knowledge demand as an important source of revenue, they have also played a fundamental role in the development of knowledge, of a conceptual-discursive as well as a practicalmanagerial nature, and its transfer. In the case of consultancies, a strong process of 
internationalisation and concentration can be observed. Universities, and some of the leading regional development agencies, have taken up similar roles as knowledge interfaces between the local and global economy, thus making a substantial contributions to the regional development discourse.

Fifth and last, the geography of the organisational field has undergone radical changes, at least in Europe. Two processes have triggered this change: devolution, and the rising importance of the European Union in the shaping and funding of regional policy (Amin and Tomaney, 1995). In most European countries, processes of devolution have greatly increased the number of sites of regional policy-making and fomented the establishment of regional development agencies, thus contributing to the complexity and diversity of the field. The EU, on the other hand, through its funding framework for regional and social policy has played a major structuring role, notably through its insistence on partnerships, comprehensive regional development strategies as part of bidding for Structural Funds and its promotion of innovation and networking as development approaches. The regional development directorate, DGXVI, has been particularly important in the emergence of "New Model" development agencies, through the direct financing of actions under the structural funds, but also through the pilot and pre-pilot actions directed by the commission under Article 10 of ERDF regulations, and through financing and encouraging a whole raft of studies, conferences, seminars and networks.

To summarise, the resulting organisational field is strongly characterised by supplyside- and partnership-oriented regional development organisations, operating on a project basis, increasingly interacting with consultants and academics, and oriented as 15

D:LDocuments and Settings\ArLalMy Documentslproductsłgeoforum7.doc 
much to new regional centres of power and to the EU as to national governments. In this context we can talk not only of "new model" regional development agencies but also of a highly isomorphic organisational field in which strong lines of communication - conferences, seminars, studies, formal networks - promote the rapid dissemination of knowledge.

\section{Following the actor: agencies and concepts}

For agents in the regional development industry, concepts are essential for how they operate in the organisational field. Concepts are enrolled for forging partnerships, shaping regional development strategies, for the mobilisation of funding and for communicating views on policy-making. Concepts have evolved, accordingly, in such a way that they reflect, absorb, and, by doing so, also shape the main interests in the field. These interests include emphases on networking (both as development target and mode), on innovation (featuring the role of SMEs and the emergence of the 'knowledge economy'), on facilitation (rather than direct subsidies), and on 'best practice' as part of the competitiveness discourse (Florida, 1995).

Concepts, accordingly, are not just intermediaries used in the communication between agents, they can be perceived as actors themselves. Through successions of associations and translations, concepts have not only changed themselves but also changed the agents using them, and thus have an impact on the organisational field. Concepts have become dominant because of the way, to use actor-network language, they have emerged from the translation of 'artefacts' into 'facts', that is, through a process of 'stabilisation' or 'black boxing'. In our field, the 'new model' concepts of regional development can be traced back to a series of regional success-stories, such 
as Silicon Valley, regions in the Third Italy, Baden-Württemberg, and the M4 corridor. These regions have been presented as excelling in economic performance, displaying high levels of innovation and a strong role of indigenous clusters, and exhibited a regional institutional configuration characterised by networking and a strategic but facilitative role for development agencies (Cooke, 1995; Cooke and Morgan, 1993, 1998).

Accompanying the portrayal of these success-stories, theoretical inspiration was sought in a blending of ideas from system-based innovation theory, institutional approaches and revived thinking on geographical agglomerations (Morgan, 1997). This led to the formulation of range of stylised 'facts', notably 'innovative milieus', 'industrial districts', 'clusters', 'regional innovation systems' and 'learning regions' (Lagendijk, 1997) - the translation of 'artefacts' into 'facts', which have become the dominant concepts of the regional development business. These stylised facts, or black boxes, are far more portable and travel far more easily than the loose accumulations of empirical observations and theoretical inspirations that they represent, making for a much more rapid diffusion through endless presentations and re-presentations in seminars, conferences and publications. The process of black boxing is illustrated by the fact that backwards associations towards the original roots are increasingly attenuated while the concepts evolve as influential actor-networks in themselves, legitimising policy actions, underpinning new funding programmes, forming the basis for new partnerships, etc. 


\section{Some Examples: Clusters and Learning Regions}

What would be required to fill out this picture is the careful tracing of the way in which concepts have evolved and then how they move around the development industry (how they are 'translated' from site to site). Such a task is beyond this paper but we can give some examples of how such an tracing or tracking could be undertaken.

\section{The Career of the Cluster}

One of the most successful regional development scripts is the cluster mapping and cluster facilitation provided by Michael Porter's firm Monitor and adopted in Europe by, among many others, the Portuguese and Basque governments, by Scottish Enterprise, and at a more localised level in North Tyneside. With its present connotation, the term 'clusters' was first used by Porter in his seminal volume The Competitive Advantage of Nations (1990). A shorthand for "clusters of competitive advantages', Porter used the concept to highlight the significance of interactions between related industries in determining the competitive position of nations and regions. The concept then proceeded to undertake a busy, fascinating tour through which it became associated with 'innovation', 'restructuring', 'networking', 'spatial agglomeration', 'supply chains', 'industrial districts', SME development, the role of industrial associations, and more. For clusters, The Competitive Advantage of Nations plays an essential role in the 'black boxing' of the concept - its capacity to act-as-one. Interestingly, in the book 'clusters' - nowhere properly defined - performs a largely supportive role in the articulation of the central 'diamond' concept. However, by building a strong link between clusters and the notion of 'competitiveness', and by 
presenting graphic cluster maps, it paved the way for the successful career of 'clusters' as a regional development concept. Porter's book thus became an important 'actant', contributing to building the 'fact' of clusters.

While the book established a starting point for the application of the concept, it is through the successive translations that the notion of 'clusters' has acquired its mobilising force. The cluster concept especially appealed to regional scientists and planners because, besides its association with 'competitiveness', it rekindled thinking about linkages between economically related activities in spatial agglomerations. In effect, while clusters were described originally as being different from sectors, it facilitated a revitalisation of sectoral policies. For this revitalisation, an important development was the association of clusters and networking (Rosenfeld, 1997; Cooke, 1995; Boekholt et al., 1993). This development deviated strongly from Porter's original work which was highly critical of the idea of networking, particularly as part of policy support. However, by becoming aligned with the notion of networking, the cluster concept could be absorbed within regional development agendas characterised by an increased emphasis on 'soft' development factors, notably collaboration and partnerships between business and development agencies. This marriage of clusters with networking was further strengthened by invoking the success stories told about Silicon Valley, Emilia Romagna, Baden Württemberg and others.

From the practical side of policy-making, the cluster concept presented an innovative approach, with low implementation costs, making it highly suitable for programmes with European funding. In addition, because of its academic embedding, the concept created a bridge between development agencies and research organisations. One 19

D:|Documents and Settings\ArLalMy Documents\productsłgeoforum7.doc 
outcome of this interaction has been that economic intelligence at the regional level has increasingly become framed along in cluster lines.

With its new baggage of networking and partnerships, the concept travelled along different routes. Clusters were particularly widely enrolled in policies dealing with economic restructuring, notably in re-mapping the sectoral composition of non-core economies such as Scotland, Tyneside, Portugal, the Basque Country and the Ruhr Area. In the UK, for instance, clusters were initially linked to policies to increase the benefits of foreign investments through nurturing supply chains and attracting further rounds of linked FDI (Young et al., 1994). Increasingly, however, clusters have become a vehicle to indigenous development.

Monitor, as part of the development industry, was important for major top-down 'mapping' exercises in the Basque Country and Scotland, among others. In the Basque Country, the cluster approach was presented as a major tool to change the business culture, to improve entrepreneurial attitudes and the interaction between firms and the technology infrastructure (Monitor Company, 1991). The approach was also mobilised by the Basque government as a way to improve its stance vis-à-vis the regional development agency (SPRI). Scottish Enterprise (SE) used the concept to give a new lease to its sectoral approaches, and to shift its focus from foreign investors to indigenous companies in established (e.g., electronics, energy, tourism, software) and emergent sectors (e.g., multimedia, biotechnology, forest products). Interestingly, although SE adopts a more micro orientation of clusters, geared to the interaction between organisations rather than industries, the term remains quite close to Porter's. SE even makes occasional references to the role of competition within clusters. 
While Monitor is, unsurprisingly, the market leader in cluster-based studies, there are now many consultancies all over the world applying the approach. An interesting example is ISA, a German union-based consultancy which uses cluster approaches as a strategy to counter the tendency among German firms to relocate activities to lowcost countries. Facilitating an alliance with the Land government, the cluster approach helped ISA to acquire a stronger position in the arena of economic development.

Besides the consultancy sector, clusters have travelled along a number of academic routes, carried over by the wide readership of Porter's publications and the subsidiary literature. One type journey can be associated with the debate on SMEs in regional development. In North Tyneside, clusters were introduced by a local university and resulted in the establishment of cluster facilitation centres, the North Tyneside Real Service Centre, a spin-off from the local council. The name of this centre was derived from regional business support agencies in Italy, showing the association with prominent cases of regional networking. The Centre's support to 'bottom-up' cluster building has received considerable recognition in the region as well as outside (for example, in the European Parliament) and, through its activities, clusters entered the vocabulary, not only of local businesses and support agencies, but also of the local press. In Northrhine Westphalia, a prominent economic development organisation is Institut Arbeit und Technik (Gelsenkirchen) (IAT), which has promoted the local cluster approach as a tool for local linkage development and inter-firm learning (Rehfeld, 1996). A major international organisation that has adopted a similar approach focused on SME linkages is UNESO, which is using the cluster notion to promote collaborative attitudes among small firms in developing countries. 
A particularly explicit example of a European policy script using clusters is offered by the RIS/RITTS handbook, which offer a practical guide for building consensus-based regional innovation strategies (European Commission, 1996). The guide gives detailed instructions of how to form various panels to co-ordinate and govern the process of strategy formulation, which combine people from different backgrounds (managers, economists, technical specialists, public sector representatives and planners). A distinction is made between the strategic panel with central overview, the international experts panel, with an important task in the evaluation procedure, and the sector panels, focusing on the support for specific clusters. In all these cases, the level of clusters has been shifted from that of industries to that of that of the firm itself, seen in a network context.

Another international organisation that over the last years has supported international collaborative work on clusters is the OECD, as part of its National Innovation System programme. The tendency has been there however to focus more on quantitative input-output models at national levels. This demonstrates increasing divergence in what 'clusters' mean to actors in different domains, which is also illustrated by the appearance of new labels, such as 'micro clusters', 'business clusters' or 'innovation clusters'. The future of the concept may well thus be one of a divorce leading to different labels.

In sum, a highly diverse group of people and organisations has emerged - academics in their research, policy makers in addressing structural economic problems, business support agencies in devising more tailored services, consultancies in developing new services, businesses confronted with questions of alliances and supply chains, readers 
and writers of the economics columns in their local newspapers - all trying to come to terms with, and use, the concept of clusters. In doing so, new definitions, new applications and new actor positions have been produced. Clusters, so writes an expert on the issue, "have the discrete charm of hard-to-define objects of desire." (Steiner, 1997, p.17). Given its regular mutations and re-definitions, it is perhaps not justified to perceive clusters as a singular 'black box'. Yet, one cannot the deny the strong mobilising force enacted by a concept which has been enrolled through so many actors in such diverse domains in the field of regional development and beyond.

\section{'Learning Regions' and 'Intelligent Regions'}

Another concept which has recently acquired a significant mobilising power in the field of regional development is the 'Learning Region'. Building on the notion of the 'learning economy' (Lundvall \& Johnson, 1994), - the idea that in our economy competitiveness is increasingly based on the capacity to develop and apply knowledge - the concept of 'Learning Regions' was coined by academic authors working in the field of innovation studies and economic geography (Florida, 1995; Morgan, 1995). In the academic arena, the 'Learning Region' presented a synthesis between new ideas from evolutionary economics - with emphasis on the institutional underpinning of systemic process of innovation and learning - and new theories on the role of spatial agglomeration. More recently, the 'Learning Region' also become associated with the role of higher education and educational organisations at the regional level (Goddard, 1998).

The Welsh case illustrates the emergence of the concept through the interaction of academics, the Welsh Development Agency (WDA) and other regional policy-makers 
and the European Commission around the development and promotion of regional innovation policy. The use of the notion in Wales emerged out of the concept 'Intelligent Region', a term which had been already applied to the region of Emilia Romagna (Cooke \& Morgan, 1991). Under this label of 'The Intelligent Region', Welsh actors and agencies participated in a wider European regional network (funded under the EU Leonardo scheme) and organised a large Conference in 1998 (see Lovering, 1999). In staging the conference, the WDA worked together with EURADA, the Brussels-based European Association of Development Agencies, which helped to promote the 'Intelligent Region' further afield through other events

The concept of a 'Learning Region' quickly travelled from innovation policy to other domains of policy-making, skill-oriented business support and higher education. A considerable number of conferences have addressed, or were even devoted to, the 'Learning Region'. One important event was the EU STRIDE Conference in March 1997, where the concept was presented as a way to improve the effectiveness of regional technology policy, based on Welsh experiences. The 'Intelligent Region' was also promoted at a conference in Graz (Austria) in November 1998, organised under the EU's Regional Information Society Initiative (RISI), and linked to the region's participation in the 'Intelligent Region' network. 'Learning region' also became a topic in various conferences on lifelong learning. Also in 1998, Tilburg University started an annual international seminar on 'Learning Regions'. Two meetings have been held so far, in which a shift can be observed from an emphasis on regional innovation to an emphasis on the role of educational institutions, particularly universities, in regional development. 
As a result of these voyages, the 'Learning Region' became a buzzword in local discourses on regional development. As in the case of clusters, an important drive for this development has been the regionalisation of governance structures, and the emphasis on partnerships, policy innovation and the need to find new sources of funding. The Learning Region concept has been enrolled to mobilise specific actors (universities, colleges, firms), through policy networks and communication with a variety of regional actors, as well the general public, and through the promotion of home regions as 'Learning Regions'. Based on a short Internet and press survey in August 1998, we have seen the concept in promotional and press clippings in the North East ("has most to gain by becoming a learning region"), Devon and Cornwall (“must become a learning region, no less"), Tartumaa ('the most rapidly learning region in the North, the designer of the New Production Era in Estonia'), Western Melbourne (Australia, "learning region committed to quality processes and outcomes"), Potomac ('promoting the region as a great place to work and live ... as a 'learning region'), Yorkshire and Humberside ("lifelong learning (...) a significant step forward in developing (...) the Learning Region”), Teesside (“university (...) as investment in the continuing development of Teesside as a 'Learning Region'”). More recently, the concept has also been invoked for promoting the new South East of England Regional Development Agency and for developing employment programmes in Bavaria, among other cases.

Why has the concept of Learning Regions had such an appeal with regional policymakers and educational institutions such as universities and colleges? For regional policy-makers, an essential point is that the concept facilitated the broadening out of 
local technology policies to areas of business development and skills improvement. The message was that the learning should become an integral process for regional businesses, organisations and individuals. An example of such an interpretation can be found in 'Learning Region Graz', where networking between 'learning companies' and 'learning organisations' forms the basis of 'learning regions'. Three main levels of learning are thus identified: (1) individual, social, and organisational learning, (2) inter-organisational and network learning, and (3) regional learning. In Graz, the 'Learning Region' concept is part of a systematic approach to innovation, grafted upon close links between business support agencies, educational institutions and local government.

The interest from universities in 'Learning Regions' stems from particular institutional reasons. Facing increased budgetary constraints, in many places accentuated by decreasing student numbers, universities have discovered their home regions as a potential source of both students and research income (see Goddard, 1999), as well as answering to the increased demands for the accountability of universities for their social and economic contribution to society. Embedding in local partnerships and strategy-making also endows the universities with social legitimacy and support. The University of Maastricht provides a good example of a university that has embraced the 'Learning Region' concept. In the opening speech of the academic year 1998-99, the Vice Chancellor of Maastricht used the concept of a 'Learning Region' not only to promote the regional embedding of the university, but also explicitly as a way to create more independence from the central state, presenting 
the 'Learning Region' as a key strategic response to the continuous budget cuts imposed upon universities.

Even more than 'clusters', perhaps, the 'Learning Region' has, over the last few years, become powerful concept in the way it mobilised various actors in the regional development arena. One can even argue that the 'Learning Region' presents more of a 'black box' - acting-as-one - than has been the case with clusters. Where, in the case of 'clusters', policy actors enrolling the concept were generally concerned about the definition of the concept - inclined to open the box somewhat - the term 'Learning Region' often remains unquestioned. There are signs that some of the actors originally promoting the concept have already distanced themselves from it. In the academic literature, one also finds increasingly fiercer criticism of the 'Learning Region' (Hudson, 1998; Lovering, 1999). These countersigns may hint at forces that will weaken the position of the 'Learning Region' and pave the way for a new dominant concept in the field of regional development.

\section{Concluding remarks}

This paper has suggested a different way for looking at our own field of work and inquiry, that of regional development. What the perspective outlined above attempts to do is to is to provide a more nuanced understanding of the mechanisms through which regional development ideas or concepts emerge, are stabilised and spread. In particular we have sought to show the key roles of resource competition, professionalisation and imitation and the fruitfulness of the concept of actor-networks - and in particular the role of enrolment and translation in the spread and take-up of ideas. 
We want to conclude this paper with some broader reflections on the regional development industry's contemporary concern with knowledge, using some of the concepts elucidated above. What are the implications of the black boxing of specific concepts discussed above for the regional development industry as an organisational field? Taking this more 'top-down' view, the 'black boxing' of the 'new model' concepts of regional development has led to what at a first glance may seem paradoxical situation. The focus on innovation, competitiveness and the shaping of particular configurations of regional institutions has led to an emphasis on variety and uniqueness as sources of regional development (Storper 1997, Malmberg and Maskell 1996). However, in the moving around of concepts, this notion of the shaping of uniqueness has become a near universal feature of the regional development business. To be effective, the broad knowledge-oriented concepts of regional development have been translated into a range of 'uniqueness scripts' which are spread, in particular, through the work of academics, consultants and the EU (for a similar point made in the context of the EU's 'information society' agenda, see Stokes, 1997).

To a certain extent, the European regional development industry's use of certain knowledge concepts or scripts thus resembles Cox and Mair's depiction of local identity scripts in the 1980s:

it seems that the same scripts are rehearsed in place after place, all that changes is the name of the locality and the famous people born there, the inventions made there, and a few key dates for local school-children to learn. Consultancy firms nevertheless manage to make business from writing such local identity scripts because each locality paradoxically 28

D:LDocuments and Settings\ArLalMy Documentslproductsłgeoforum7.doc 
seeks uniqueness by copying others - but by being 'the best.' (Cox and Mair, 1991, p. 207)

On closer inspection, however, the universal emphasis on uniqueness is not a real paradox, since it involves different levels of knowledge: 'universal' refers to the fact that similar concepts and scripts are moving around in the world of regional development policy; 'unique' refers to the knowledge embedded in the regional economy, that is, in firms and the regional institutions working with them. What this combination of perspectives points to, and what seems to be ignored in much of the literature on regional development, is the strong tendency towards convergence and institutional isomorphism stemming directly from this stress on particular forms of uniqueness.

In reflecting on the impact of the 'new model' concepts of regional development, however, another, perhaps more serious, paradox can be observed. This paradox, we would suggest, may well present the beginning of the erosion and dissolution of the currently dominating 'black boxes'. Not only has the emphasis on uniqueness led to a universal search for localised strategies of knowledge creation and application, it has also generated a discourse of 'protection', prevention of knowledge leakage and ‘safeguards against imitation' (Malmberg and Maskell, 1997, p.30). Michael Storper, for example, asserts that 'firms or territorial economies must therefore be equipped to keep outrunning the powerful forces of imitation in the world economy' (Storper, 1997, p. 250). 
The irony is that a strongly isomorphic field, such as the regional development industry, is increasingly replete with mechanisms that are intended to support the powerful forces of imitation, the black boxing of concepts and their transfer from region to region. Both national governments and the EU are keen on promoting technology transfer and 'best practice' between regions and curbing detrimental forms of interregional competition. Regional development agencies following a strategy of maximising their benefit from 'uniqueness' through preventing imitation and leakages may thus face problems of legitimisation and accountability. We see this, more fundamental, paradox as generating conflicts which may, in the long run, weaken the power of the 'new model' concepts of regional development.

\section{Notes}

${ }^{1} \mathrm{We}$ are, of course, aware that inward investment remains a, and in some cases the, main focus of regional development agencies in a number of European regions. 


\section{References}

Amin, A. and Tomaney, J. (1995) Behind the Myth of European Union. Routledge, London.

Boekholt, P., Fahrenkrog, G., Jacobs, D., Howells, J. (1993) Clusters and networks of innovative SMEs. Background paper for the Policy Forum workshop, Brussels, December 1993.

Callon, M. (1991) Techno-economic networks and irreversibility. In A Sociology of Monsters, Ed. J. Law, pp. 132-161. Routledge, London.

Callon, M. (1997) Actor-network theory - the market test. Paper presented at the 'Actor $\begin{array}{llll}\text { Network and } \quad \text { After' } & \text { Workshop, July }\end{array}$ (http://www.keele.ac.uk/depts/stt/cstt2/ant/callon.htm).

Clegg, S. (1997) Frameworks of Power. Sage, London.

Cooke, P. (1995) Introduction. Chap. 1. In: The Rise of the Rustbelt. (Ed: Cooke, P.). UCL Press, London, pp. 1-19.

Cooke, P. (1995) Keeping to the high road: learning, reflexivity and associative governance in regional economic development. In The Rise of the Rustbelt. Ed. P. Cooke, pp. 231-245. UCL Press, London.

Cooke, P. and Morgan, K. (1993) The network paradigm: new departures in regional development. Environment and Planning D: Society and Space 11, 543-564. 
Cooke, P. and Morgan, K. (1998) The Associational Economy: Firms, Regions and Innovation. Oxford University Press, Oxford.

Cooke, P., Morgan, K. (1991) The intelligent region: industrial and institutional innovation in Emilia-Romagna. (Series Regional and Industrial Research Report, 7.) University of Wales, Cardiff.

Cox, K. R. and Mair, A.(1991) From localised social structures to localities as agents. Environment and Planning A: 23, 197-213.

Demarest, M. (1997) Understanding knowledge management. Long Range Planning, 30(3), 374-384.

DiMaggio, P. and Powell, W.W. (1983) The iron cage revisited: institutional isomorphism and collective rationality in organizational fields. American Sociological Review 48, 147-160.

European Commission (1996) Practical Guide to Region Innovation Actions. Office for Official Publications of the European Communities, Luxembourg.

Florida, R. (1995) Toward the learning region. Futures 27, 527-536.

Gibbons, M., Limoges, C., Nowotny, H., Schwartzman, S., Scott, P. and Trow, M. (1994) The New Production of Knowledge. Sage, London.

Goddard, J (1998) Universities and Regional Development. Report to the Department for Education and Employment, February. 
Goddard, J (1999) The Response of Higher Education Institutions to Regional Needs. A report to the Centre for Educational Research and Innovation's Programme on Institutional Management in Higher Education, Newcastle Upon Tyne, CURDS/University of Newcastle.

Halkier, H. and Damborg, C. (1997) Networks, development agencies and intelligent regions. Towards a framework for empirical analysis. Aalborg University. European Research Unit. Series of Occasional Papers 22, 1-27.

Halkier, H. and Danson, M. (1996) Development agencies and new-model regional policy. A survey of trends in 30 European regions. Paper presented to the European Urban and Regional Studies Conference, Durham, 11-14 April.

Henry, N., Pinch, S. and Russell, S. (1996) In pole position - untraded interdependencies, new industrial spaces and the British motor sport industry. Area 28, 25-36.

Hudson, R. (1998) The learning economy, the learning firm and the learning region: a sympathetic critique of the limits to learning. Paper presented to the RGS/IBG Annual Conference, Kingston University, 5-8 January 1998.

Lagendijk, A. (1997) From new industrial spaces to regional innovation systems and beyond. How and from whom should industrial geography learn? EUNIT Discussion Paper Series No,10.

Latour, B. (1987) Science in Action: How to Follow Scientists and Engineers Through Society. Open University Press, Milton Keynes. 
Latour, B. (1997) On actor-network theory: a few clarifications. Paper presented at the ‘Actor Network and After' Workshop, July 1997 (http://www.keele.ac.uk/depts/stt/cstt2/ant/latour.htm).

Law, J. (1991) Introduction: monsters, machines and sociotechnical relations. In $A$ Sociology of Monsters, Ed. J. Law, pp. 1-23. Routledge, London.

Lovering, J. (1999) Theory led by policy: The inadequacies of 'The New Regionalism'. International Journal of Urban and Regional Research 22, forthcoming.

Lundvall, B.-Å. and Johnson, B. (1994) The learning economy. Journal of Industry Studies 1, 23-42.

Malmberg, A. and Maskell, P. (1996) Towards an explanation of regional specialization and industry agglomeration. European Planning Studies 5, 25-41.

Monitor Company (1991) La ventaja competitiva de Euskadi. FASE I. Indentificación del potencial de competitividad. Ekonomiaz 21, 156-209.

Morgan, K. (1995) The learning region. Institutions, innovation and regional renewal. Papers in Planning Research 157, 1-33.

Morgan, K. (1997) The learning region: institutions, innovation and regional renewal. Regional Studies 31, 491-503.

OECD (1996) The Knowledge-based Economy. OECD, Paris.

Porter, M.E. (1990) The competitive advantage of nations. Macmillan, London. 
Rehfeld, D. (1996) Produktionscluster and räumliche entwicklung. Beispiele und konsequenzen. Institut Arbeit und Technik, Wissenschaftszentrum NordrheinWestfalen.

Rosenfeld, S. A. (1996) Does co-operation enhance competitiveness - assessing the impacts of interfirm collaboration. Research Policy 25, 247-263.

Rosenfeld, S.A. (1997) Bringing business clusters into the mainstream of economic development. European Planning Studies 5, 3-23.

Steiner, M. (Ed.) (1997) Competence clusters. Workshop report. Graz and Al-Ring Austria, November 21-22, 1996. Leykam, Graz.

Stokes, C. (1997) Singing off the same hymn sheet: "prepare ye the way of the information-society application.' unpublished paper, Centre for Science Studies and Science Policy, University of Lancaster.

Storper, M. (1997) Regional economies as relational assets. In Geographies of Economies, Eds. R. Lee and J. Wills, pp. 248-259. Arnold, London.

Young, S., Hood, N., Peters, E. (1994) Multinational enterprises and regional economic development. Regional Studies 28, 657-677. 